\title{
Study Data Tabulation Model Implementation Guide Version
}

National Cancer Institute

\section{Source}

National Cancer Institute. Study Data Tabulation Model Implementation Guide Version. NCl Thesaurus. Code C156604.

The version of the CDISC Study Data Tabulation Model implementation guide that is being used in the study submission. 